\title{
Cultural diversity should be taught: a reply to UK medical students' view on interacting with multicultural patients
}

\author{
Lauren Nirta ${ }^{1}$ and HyeRin Roh $^{1,2}$ \\ ${ }^{1}$ Department of Medical Education and ${ }^{2}$ Institute for Medical Humanities, Inje University College of Medicine, \\ Busan, Korea
}

We reported our experiences implementing a cultural diversity (CD) education program in Korea in "Medical students interact with multicultural patients to learn cultural diversity" [1]. London-based medical students, Dost et al. [2] responded to our publication in a commentary entitled "View of UK medical students on interacting with multicultural patients: is it a natural or a taught skill?" [2]. They believe that understanding ethnic diversity and encouraging healthcare workforce diversity is helpful for patient care. They claim that they did not receive any formal CD education. Additionally, they argue that they do not need formal $\mathrm{CD}$ education because they live in London, which has an ethnically, racially, and religiously diverse population. They maintain that London-based students naturally develop awareness and understanding of different cultures and beliefs through their interactions both in and out of clinics. However, they also assert that medical students studying in places with less exposure to a variety of cultures need to be taught $\mathrm{CD}$.

We sincerely appreciate the students' feedback and perspectives. While we cannot comment on the diversity components of the students' own curriculum, we do feel they misunderstood the concept of $\mathrm{CD}$ and $\mathrm{CD}$ education. Here, we would like to present our response focusing on the following two points: First, CD extends beyond understanding ethnic differences. Second, all medical students should receive CD education.

\section{Cultural diversity extends beyond ethnic differences}

In our view, Dost et al. [2] reduce $\mathrm{CD}$ to ethnic diversity, and present religion as a biproduct of ethnicity. Using the example of 'Bangladeshi Muslims,' the students indicate that $\mathrm{CD}$ education is limited to 'attempting to teach the characteristic health behaviors of specific groups, such as 'specific types of food and dress patients might require due to religious reasons.' This misconception is a common starting point for students' understanding of $\mathrm{CD}$ education. However, when ethnicity is disproportionately emphasized in comparison with other aspects of culture, the concept of what should be
Received: April 25, 2019 • Revised: May 14, 2019 • Accepted: May 14, 2019 Corresponding Author: HyeRin Roh (https://orcid.org/0000-0002-3879-709X) Department of Medical Education and the Institute for Medical Humanities, Inje University College of Medicine, 75 Bokji-ro, Busanjin-gu, Busan 47392, Korea

Tel: +82.51.890.8811 Fax: +82.51.893.9600 email: hyerinr@gmail.com
Korean J Med Educ 2019 Jun; 31(2): 173-176.

https://doi.org/10.3946/kjme.2019.128

eISSN: 2005-7288

(C) The Korean Society of Medical Education. All rights reserved. This is an open-access article distributed under the terms of the Creative Commons Attribution Non-Commercial License (http:// creativecommons.org/licenses/by-nc/3.0/), which permits unrestricted non-commercial use, distribution, and reproduction in any medium, provided the original work is properly cited. 
taught deteriorates. Prescriptive approaches to $\mathrm{CD}$ education, which reduce culture to a static list of traits that can be observed and learned by outsiders, fail to recognize that different people interpret the world differently [3]. Such approaches have been shown to enforce stereotypes and prejudices by focusing too closely on differences, and do not result in attitude change [3-5].

Culture is a multidimensional and dynamic concept that makes up an individual's sense of self [3]. It is the shared systems of learned values, beliefs, behaviors, and meanings that can influence how patients and health care professionals perceive health and illness, and how they interact with each other $[5,6]$. Culture is defined by each person in relationship to the groups that they identify with $[3,6]$. It includes differences of age or generation, gender, sexual orientation, occupation and socioeconomic status, ethnic origin, religious or spiritual beliefs, disability [4], and experience [5]. As we mentioned in our paper, our paradigm is based on the premise that each person cannot be stereotyped as any one of their various cultural backgrounds. Our guests represented diversity in ethnicity, gender, socioeconomic background, education, religion, and experiences including immigration, marital status (including being married to a Korean or non-Korean spouse), parenthood, and others [1].

Indeed, in our program we placed a heavy emphasis on ethnic diversity. However, this was not because CD is ethnic diversity, but because we believe ethnic diversity is the most current emerging diversity issue in Korea [7]. We believe every country has their own emerging issues related to various groups including refugees, the LGBT (Lesbian, Gay, Bisexual, and Transgender) community, people with AIDS, underserved communities, women, and so on. We note that issues related to diversity are fluid and thus should be re-evaluated over time. We recommend focusing on the most appropriate issues related to diversity depending on the national or regional contexts where the $\mathrm{CD}$ education takes place.

\section{Cultural diversity education extends beyond teaching cultural differences}

Doctors should be health advocates for all people, including members of minority groups. However, even a doctor with knowledge and understanding of cultural differences may still create barriers to clinical effectiveness because of their own prejudice, stereotyping, or assumptions [8]. For example, people in Korea often assume that all Caucasians speak English but cannot speak Korean. Doctors holding this stereotype may persist in speaking English to patients from Europe or South America who cannot understand English but can often speak Korean. In another example, some people in Korea hold the stereotype that South East Asians are migrant workers and are poor and uneducated. As such, doctors sometimes minimize treatment or diagnostic tests for South East Asian patients to avoid expensive medical bills, without consulting the patient about their financial circumstances. In both scenarios, the patient is disempowered and excluded from participating in their own care. These are Korean examples, however, doctors in other countries may also impose their unconscious prejudice, stereotyping, or assumptions with similar effect.

The inherent power imbalance between doctors and patients can hinder respect for diversity and threaten the cultural safety of patients [8]. Cultural safety is care that respects all aspects of a person's identity, empowers the patient to participate in their own care, and is determined as safe by the recipients of care [4]. Having relationships with culturally diverse people in the community is not the same as having relationships with culturally diverse patients in the clinical environment. 
Even a person whose prejudices do not negatively impact their social relationships with culturally diverse family or friends may inadvertently harm their patients' cultural safety. Cultural unsafety not only places the patient at risk for poor disease management, but when a patient's culture is ignored by a doctor, and they are not permitted to participate in their own care, the power imbalance is magnified. As a result, treatment adherence is often significantly reduced, and the patient may disengage from the health-care system, even at significant risk to themselves [8].

Since the 1990s, CD education has incorporated topics related to social, structural and power inequities; disparities in healthcare; and developing an awareness about one's own implicit attitudes, beliefs and assumptions as they influence the cultural safety of patients $[3,4,6]$. The first step towards developing an appropriate attitude towards $\mathrm{CD}$ is accepting the need to recognize and appropriately address cultural bias in oneself and others [3,9], and fostering insight into the power imbalance between doctor and patient [8]. This is the niche our program occupies, and it involves students acknowledging that they do not yet have the tools and knowledge to maintain the cultural safety of patients [9]. Our learning outcomes focused on recognizing the impact of the students' own perspectives, attitudes, assumptions, stereotypes, and prejudices toward patients' culture on their delivery of healthcare [1]. This is in line with the guidelines and principles that underpin the teaching of CD to medical undergraduates [3].

To respond to the London-based students' question: it is essential that $\mathrm{CD}$ be taught to all medical students, regardless of whether learning takes place in a multi- or mono-cultural environment. CD training helps doctors and medical students to examine power imbalances and the impact of their own inherent prejudices, stereotypes, and beliefs on the delivery of health care to culturally diverse patients. Relevant diversity issues should be emphasized in the curriculum according to the national or regional agenda where learning takes place.

\section{ORCID:}

Lauren Nirta: https://orcid.org/0000-0001-6432-7801;

HyeRin Roh: https://orcid.org/0000-0002-3879-709X

Acknowledgements: The authors would like to extend their sincere thanks and gratitude to the experts, guests and students who participated in this program and provided their valuable feedback.

Funding: No funding was provided for this research.

Conflicts of interest: No potential conflict of interest relevant to this article was reported.

Author contributions: Conception and design of the work: LN, HR; drafting the article: LN; editing the article together: $\mathrm{HR}, \mathrm{LN}$; and critical revision of the article: HR, LN.

\section{References}

1. Roh H, Nirta L. Medical students interact with multicultural patients to learn cultural diversity. Korean J Med Educ. 2018;30(2):161-166.

2. Dost S, Master B, Momin S, Najjar A, Jamshaid F, Kassam Z. View of UK medical students on interacting with multicultural patients: is it a natural or a taught skill? Korean J Med Educ. 2018;30(3):261-263.

3. Dogra N, Bhatti F, Ertubey C, et al. Teaching diversity to medical undergraduates: curriculum development, delivery and assessment: AMEE guide no. 103. Med Teach. 2016;38(4):323-337.

4. Kurtz DL, Janke R, Vinek J, Wells T, Hutchinson P, Froste A. Health sciences cultural safety education in Australia, Canada, New Zealand, and the United States: 
a literature review. Int J Med Educ. 2018;9:271-285.

5. Knipper M, Seeleman C, Essink-Bot ML. How should ethnic diversity be represented in medical curricula?: a plea for systematic training in cultural competence. GMS Z Med Ausbild. 2010;27(2):Doc26.

6. Dogra N. Cultural diversity teaching in the medical undergraduate curriculum. Divers Health Soc Care. 2005;2(3);233-245.

7. Diversity of Cultural Expressions, UNESCO. Republic of Korea 2018 report: executive summary. https://en.unesco.org/ creativity/governance/periodic-reports/2018/republic-kore a. Published August 22, 2018. Accessed April 22, 2019.

8. Laverty M, McDermott DR, Calma T. Embedding cultural safety in Australia's main health care standards. Med J Aust. 2017;207(1):15-16

9. Crandall SJ, George G, Marion GS, Davis S. Applying theory to the design of cultural competency training for medical students: a case study. Acad Med. 2003;78(6): 588-594. 